\title{
MENAKAR DETERMINAN KINERJA KARYAWAN
}

\section{Arbi Leo Baskoro, Sri Yuni Widowati, Aprih Santoso}

Fakultas Ekonomi

Universitas Negeri Semarang

\section{A R T IC LE IN F O}

\section{Keywords: work facilities, leadership, competence, division of labor and employee performance}

Kata Kunci: fasilitas kerja, kepemimpinan, kompetensi, pembagian kerja dan kinerja karyawan.

Corresponding author : Aprih Santoso aprihsantoso@usm.c.id
Abstract: The population in this study were all marketing employees of PT. Borobudur Oto Mobil which amounted to 36 employees and the sampling technique used in this study was the census method and the analysis tool used in this study was multiple linear regression. The regression test results show that the variables of work facilities, leadership, competence and division of labor have a positive effect on employee performance and the results of hypothesis testing indicate that the variables of work facilities, leadership, competence and division of labor have a significant effect on employee performance. The results of the determination test produce the adjusted $R$ square value in the regression model obtained at 0.610 which means that 61 percent of employee performance variables can be explained by variables of work facilities, leadership, competence and division of labor and the results of the accuracy test table obtained 0,000 smaller than 0, 05 which means that employee performance variables can be jointly explained by leadership variables, work facilities, competencies and division of labor.

Abstrak: Populasi dalam penelitian ini adalah seluruh karyawan marketing PT. Borobudur Oto Mobil yang berjumlah 36 karyawan dan teknik pengambilan sampel yang digunakan dalam penelitian ini adalah metode sensus serta alat analisis yang digunakan dalam penelitian ini regresi linier berganda. Hasil pengujian regresi menunjukkan bahwa variabel fasilitas kerja, kepemimpinan, kompetensi dan pembagian kerja berpengaruh positif terhadap kinerja karyawan dan hasil pengujian hipotesis menunjukkan bahwa variabel fasilitas kerja, kepemimpinan, kompetensi dan pembagian kerja berpengaruh signifikan terhadap kinerja karyawan. Hasil uji determinasi menghasilkan nilai adjusted $\mathrm{R}$ square pada model regresi diperoleh sebesar 0,610 yang artinya 61 persen variabel kinerja karyawan dapat dijelaskan oleh variabel fasilitas kerja, kepemimpinan, kompetensi dan pembagian kerja serta hasil uji ketepatan model tabel tersebut diperoleh tingkat signifikansi 0,000 lebih kecil dari 0,05 yang artinya bahwa variabel kinerja karyawan dapat secara bersama-sama dijelaskan oleh variabel kepemimpinan, fasilitas kerja, kompetensi dan pembagian kerja. 


\section{Latar Belakang}

\section{PENDAHULUAN}

Karyawan merupakan sumber daya manusia yang paling berharga didalam semua organisasi.Tanpa adanya karyawan yang berkualitas tidak mungkin tujuan organisasi dapat tercapai dengan baik.Organisasi dilakukan dalam suatu sistem yang terdiri dari aktivitas- aktivitas yang dilakukan secara teratur dan berulang-ulang oleh sekelompok orang untuk mencapai tujuan bersama.Untuk mencapai tujuan tersebut, sebuah organisasi harus didukung oleh sumber-sumber daya yang berkualitas baik dari berwujud material, modal maupun manusia.

Fasilitas kerja merupakan suatu bentuk pelayanan terhadap karyawan agar menunjang kinerja dalam memenuhi kebutuhan karyawan, sehingga dapat meningkatkan kinerja (Mangkunegara,2012). Fasilitas kerja ini merupakan suatu bentuk pelayanan perusahaan terhadap karyawan agar menunjang kinerja dalam memenuhi kebutuhan karyawan, sehingga dapat meningkatkan kinerja kerja pegawai.Adanya fasilitas kerja yang disediakan oleh organisasi sangat mendukung pegawai dalam bekerja.Sementara Djoyowirono (2015) menyatakan bahwa fasilitas kerja adalah alat yang diperlukan untuk menggerakkan kegiatan manajemen dalam rangka mencapai tujuan organisasi.Fasilitas kerja merupakan faktor- faktor yang tidak dapat dipisahkan dari dunia kerja dan merupakan hal yang vital bagi pegawaiuntuk menyelesaikan tugas-tugasnya.Dengan tersedianya fasilitas berupa sarana dan prasarana penunjang kerja yang lengkap maka pegawai anak terdorong untuk meningkatkan kinerjanya.

Tabel 1 Realisasi Penjualan Colt Diesel FE74 HDV PT. Borobudur Oto Mobil

\begin{tabular}{cccc}
\hline Tahun & Target & Realisasi & Persen \\
\hline 2015 & 10368 & 8813 & 85,00 \\
2016 & 15552 & 10575 & 68,00 \\
2017 & 20736 & 18975 & 91,51 \\
\hline
\end{tabular}

Sumber: PT. Borobudur Oto Mobil,2018

Dari tabel tersebut, karyawan sales tidak bisa mencapai target yang telah ditetapkan oleh perusahaan, masalah tersebut mengindikasikan adanya penurunan kinerja karyawan sales PT. Borobudur Oto Mobil, sehinggan rumusan masalahnya adalah bagaimana meningkatkan kinerja karyawan agar mencapai target?

\section{TINJAUAN PUSTAKA}

\section{Kinerja Karyawan}

Kinerja seorang karyawan pada dasarnya adalah hasil kerja seorang karyawan selama periode tertentu dibandingkan dengan hasil yang telah dicapai seperti : standar, target atau sasaran atau kriteria yang telah ditentukan dan disepakati bersama. Kinerja adalah suatu hasil kerja yang dicapai seseorang dalam melaksanakan tugas- tugas yang dibebankan kepadanya yang didasarkan atas kecakapan, pengalaman, kesungguhan serta waktu (Alwi, 2012). Konsepkinerja pada dasarnya dapat dilihat dari dua segi, yaitu kinerja pegawai (per-individu) dan kinerja organisasi. Kinerja dikatakan sebagai sebuah hasil (output) dari suatu proses tertentu yang dilakukan oleh seluruh komponen organisasi terhadap sumber-sumber tertentu yang digunakan (input).

\section{Kompetensi}

Seseorang dalam menyelesaiakan suatu pekerjaan banyak dipengaruhi oleh kemampuannya dalam bidang pekerjaan tersebut.Oleh karena itu, agar pekerjaan tersebut dapat diselesaikan dengan baik harus dikerjakan oleh orang yang memiliki kompetensi dibidang pekerjaan yang dimaksud. Muhaimin (2011) menyatakan kompetensi adalah seperangkat tindakan intelegen penuh tanggung jawab yang harus dimiliki seseorang sebagai syarat untuk dianggap mampu melaksanakan tugas-tugas dalam bidang pekerjaan tertentu. Gulo (2012) berpendapat bahwa kompetensi terdiri dari dua aspek yang saling berinteraksi, yaitu aspek yang tampak atau yang disebut performance dan aspek yang tidak tampak atau yang disebut aspek rasional. Performance ditunjukan dalam bentuk tingkah laku yang dapat didemonstrasikan sehingga dapat dilihat, diamati dan dirasakan. Aspek rasional tidak dapat diamati karena tidak tampil dalam bentuk prilaku empiris. Ahsan (2011) mengemukakan bahwa sebagai

pengetahuan, keterampilan, dan kemampuanyang dikuasai oleh seseorang yang telah menjadi bagian dari 
dirinya, sehingga dapat melakukan perilaku-perilaku kognitif, afektif, dan psikomotorik dengan sebaik-baiknya. Dalam melakukan suatu aktivitas perusahaan selalu membutuhkan manajemen. Organisasi merupakan alat untuk mencapai tujuan manajemen yang baik dan efektif, maka pembagian kerja dalam organisasi perlu dibagi- bagi pada karyawan sesuai kebutuhan organisasi tersebut, oleh karena itu, perlu adanya pembagian kerja dan penyusunan pembagian kerja (Mangkunegara, 2011). Manfaat pembagian dan penyusunan kerja yaitu agar suatu pekerjaan dapat terselenggara dengan baik sesuai rencana dan dapat diketahui dengan jelas tujuan organisasi, dan pegawai yanga bertanggung jawab atas terselenggaranya pekerjaan tersebut.

\section{Hubungan Logis Antar Variabel Penelitian dan Perumusan Hipotesis Pengaruh Fasilitas Kerja terhadap Kinerja Karyawan}

Fasilitas kerja merupakan suatu bentuk pelayanan bagi instansi terhadap karyawan agar menunjang kinerja dalam memenuhi kebutuhan karyawan, sehingga dapat meningkatkan kinerja karyawan (Robbins,2013). Fasilitas kerja ini merupakan suatu bentuk pelayanan perusahaan terhadap karyawan agar menunjang kinerja karyawan. Hasil penelitian Sri Wahyuni (2014) dan Isnan Munawirsyah (2017) menyatakan fasilitas kerja berpengaruh positif dan signifikan terhadap kinerja karyawan.Berdasarkan uraian diatas, maka hipotesis penelitian ini adalah :

$\mathrm{H}_{1}$ : Fasilitas kerja berpengaruh terhadap kinerja karyawan

\section{Pengaruh Kepemimpinan Terhadap Kinerja Karyawan}

Young (2011) menyatakan kepemimpinan merupakan bentuk dominasi yang didasari atas kemampuan pribadi yang sanggup mendorong atau mengajak orang lain untuk berbuat sesuatu yang berdasarkan penerimaan oleh kelompoknya, dan memiliki keahlian khusus yang tepat bagi situasi yang khusus. Hasil penelitian Chairuddin Surya Putra (2014) dan Estu Aprilian (2017) menyatakan kepemimpinan berpengaruh positif dan signifikan terhadap kinerja karyawan. Berdasarkan uraian diatas, maka hipotesis penelitian ini adalah :

$\mathrm{H}_{2}$ : Kepemimpinan berpengaruh terhadap kinerja karyawan

\section{Pengruh Kompetensi terhadap Kinerja Karyawan}

Gulo (2012) berpendapat kompetensi terdiri dari dua aspek yang saling berinteraksi, yaitu aspek yang tampak atau yang disebut performance dan aspek yang tidak tampak atau yang disebut aspek rasional. Performance ditunjukan dalam bentuk tingkah laku yang dapat didemonstrasikan sehingga dapat dilihat, diamati dan dirasakan. Aspek rasional tidak dapat diamati karena tidak tampil dalam bentuk perilaku empiris. Ahsan (2011) mengemukakan bahwa sebagai pengetahuan, keterampilan, dan kemampuan yang dikuasai oleh seseorang yang telah menjadi bagian dari dirinya, sehingga dapat melakukan perilaku-perilaku kognitif, afektif, dan psikomotorik dengan sebaik-baiknya. Hasil penelitian Faustyna (2014) dan Fansyuri Ilham Mudayana (2016) menyatakan bahwa kompetensi berpengaruh positif dan signifikan terhadap kinerja karyawan. Berdasarkan uraian diatas, maka hipotesis penelitian ini adalah:

$\mathrm{H}_{3}$ : Kompetensi berpengaruh terhadap kinerja karyawan

\section{Pengaruh Pembagian Kerja terhadap Kinerja Karyawan}

Pophal (2008) menyatakan pembagian kerja merupakan rekaman tertulis mengenai tanggung jawab dari pekerjaan tertentu. Hasil penelitian Ferdy Roring (2017) dan Farlane S. Rumokoy (2016) menyatakan pembagian kerja berpengaruh positif dan signifikan terhadap kinerja karyawan. Berdasarkan uraian diatas, maka hipotesis penelitian ini adalah :

$\mathrm{H}_{4}$ : Pembagian kerja berpengaruh terhadap kinerja karyawan. 


\section{METODOLOGI PENELITIAN}

Dalam penelitian ini variabel yang digunakan adalah : (1) Variabel bebas : fasilitas kerja, kepemimpinan, kompetensi dan pembagian kerja. (2) Variabel rerikat kinerja karyawan. Populasinya adalah seluruh karyawan marketing PT. Borobudur Oto Mobil berjumlah 36 karyawan yang sekaligus sebagai sampel, menggunakan teknik sensus. Prinsip pokok teknik analisis kuantitatif adalah mengolah dan menganalisis datadata yang terkumpul menjadi data yang sistematik, terstruktur, teratur, dan mempunyai makna. Adapun uij yang digunakan adalah : Uji Validitas, Uji Reliabilitas. Uji Normalitas, Uji Multikolonieritas, Uji Heteroskedasitas, Uji Hipotesis (Uji F dan t), Koefisien Determinasi dan Regresi Linier Berganda, dengan persamaan regresinya adalah sebagai berikut:

$$
\mathrm{Y}=\mathrm{a}+\mathrm{b} 1 \mathrm{X} 1+\mathrm{b} 2 \mathrm{X} 2+\mathrm{b} 3 \mathrm{X} 3+\mathrm{b} 4 \mathrm{X} 4+\mathrm{e}
$$

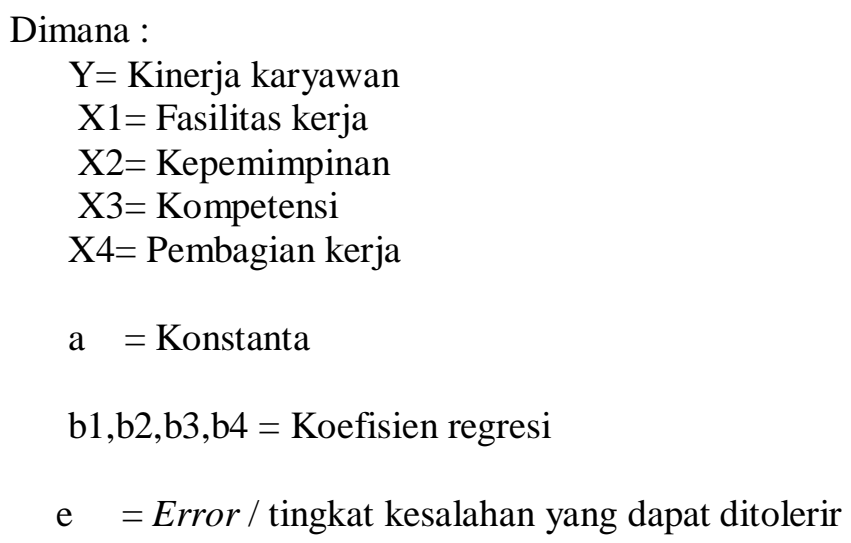

\section{Hasil Penelitian}

\section{HASIL PENELITIAN DAN PEMBAHASAN}

\section{Pengujian Hipotesis}

Hasil pengujian hipotesis sebagai berikut:

\section{Tabel 2 Hasil Uji Hipotesis}

\section{Coefficientsa}

\begin{tabular}{|c|c|c|c|c|c|c|}
\hline \multirow[b]{2}{*}{ Model } & \multicolumn{2}{|c|}{$\begin{array}{l}\text { Unstandardized } \\
\text { Coefficients }\end{array}$} & \multirow{2}{*}{$\begin{array}{c}\begin{array}{c}\text { Standardized } \\
\text { Coefficients }\end{array} \\
\text { Beta }\end{array}$} & \multirow[b]{2}{*}{ Sig. } & \multicolumn{2}{|c|}{$\begin{array}{c}\text { Collinearity } \\
\text { Statistics }\end{array}$} \\
\hline & B & Std. Error & & & $\begin{array}{c}\text { Toleranc } \\
\mathrm{e}\end{array}$ & VIF \\
\hline $\begin{array}{c}1 \\
\text { (Constant) }\end{array}$ & - & 2.591 & & .118 & & \\
\hline & $\begin{array}{l}.27 \\
9\end{array}$ & .108 & .281 & .014 & .948 & 1.055 \\
\hline $\begin{array}{l}\text { Fasilitas Kerja } \\
\text { Kepemimpina } \\
\text { n Kompetensi }\end{array}$ & $\begin{array}{l}.21 \\
9\end{array}$ & .062 & .392 & .001 & .893 & 1.120 \\
\hline $\begin{array}{l}\text { Pembagian } \\
\text { Kerja }\end{array}$ & $\begin{array}{l}.17 \\
4\end{array}$ & .075 & .265 & .026 & .859 & 1.165 \\
\hline & $\begin{array}{l}.27 \\
4\end{array}$ & .085 & .351 & .003 & .929 & 1.076 \\
\hline
\end{tabular}

Sumber : Data primer yang diolah, 2018 


\section{Uji Hipotesis Fasilitas Kerja Terhadap Kinerja Karyawan}

Nilai signifikansi hasil sebesar 0,014 lebih kecil dari 0,05. Hasil tersebut menunjukkan bahwa hipotesis 1 dalam penelitian ini diterima, yang artinya bahwa fasilitas kerja berpengaruh secara signifikan terhadap kinerja karyawan.

\section{Uji Hipotesis Kepemimpinan Terhadap Kinerja Karyawan}

Nilai signifikansi hasil sebesar 0,001 lebih kecil dari 0,05. Hasil tersebut menunjukkan bahwa hipotesis 2 dalam penelitian ini diterima, yang artinya bahwa kepemimpinan berpengaruh secara signifikan terhadap kinerja karyawan.

\section{Uji Hipotesis Kompetensi Terhadap Kinerja Karyawan}

Nilai signifikansi hasil sebesar 0,026 lebih kecil dari 0,05. Hasil tersebut menunjukkan bahwa hipotesis 3 dalam penelitian ini diterima, yang artinya kompetensi berpengaruh secara signifikan terhadap kinerja karyawan.

\section{Uji Hipotesis Pembagian kerja Terhadap Kinerja Karyawan}

Nilai signifikansi hasil sebesar 0,003 lebih kecil dari 0,05. Hasil tersebut menunjukkan bahwa hipotesis 4 dalam penelitian ini diterima, yang artinya pembagian kerja berpengaruh secara signifikan terhadap kinerja karyawan.

Koefisien Deteterminasi $\left(\mathbf{R}^{2}\right)$

Tabel 3 Hasil Uji Koefisien Determinasi

Model Summaryb

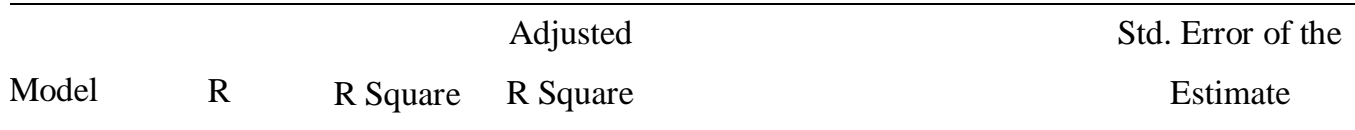

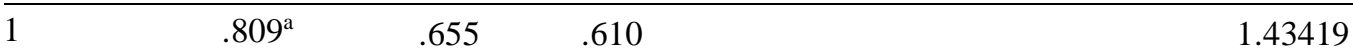

a. Predictors: (Constant), Pembagian Kerja, Kepemimpinan, Fasilitas Kerja, Kompetensi

b. Dependent Variable: Kinerja Karyawan

Model Summary ${ }^{b}$

\begin{tabular}{lrrrr}
\hline Model & R & R Square & $\begin{array}{c}\text { Adjusted } \\
\text { R Square }\end{array}$ & $\begin{array}{c}\text { Std. Error of the } \\
\text { Estimate }\end{array}$ \\
\hline 1 & $.809^{\mathrm{a}}$ & .655 & .610 & 1.43419 \\
\hline
\end{tabular}

a. Predictors: (Constant), Pembagian Kerja, Kepemimpinan, Fasilitas Kerja, Kompetensi

b. Dependent Variable: Kinerja Karyawan

Sumber : Data primer yang diolah,2018

Tabel tersebut menunjukkan bahwa nilai adjusted $R$ square pada model regresi diperoleh sebesar 0,610 yang artinya 61 persen variabel kinerja karyawan dapat dijelaskan oleh variabel fasilitas kerja, kepemimpinan, kompetensi dan pembagian kerja sedangkan sisanya sebesar 49 persen dijelaskan oleh variabel lain diluar penelitian ini. 


\section{Uji F}

\section{Tabel 4 Uji F}

\begin{tabular}{lrrrrr} 
& & \multicolumn{3}{c}{ ANOVA $^{\mathbf{b}}$} \\
\hline Model & $\begin{array}{c}\text { Sum of } \\
\text { Squares }\end{array}$ & df & $\begin{array}{c}\text { Mean } \\
\text { Square }\end{array}$ & F & Sig. \\
\hline 1 Regression & 120.986 & 4 & 30.247 & 14.705 & $.000^{\mathrm{a}}$ \\
Residual & 63.764 & 31 & 2.057 & & \\
Total & 184.750 & 35 & & & \\
\hline
\end{tabular}

a. Predictors: (Constant), Pembagian Kerja, Kepemimpinan, Fasilitas Kerja, Kompetensi

b. Dependent Variable: Kinerja Karyawan

Sumber : Data primer yang diolah,2018

Dari hasil uji ketepatan model tabel tersebut diperoleh nilai $\mathrm{F}$ adalah sebesar 14.705 dengan tingkat signifikansi 0,000. Jika dilihat dari nilai signifikansi tersebut diperoleh bahwa nilai signifikansi $F$ lebih kecil dari 0,05. Hal ini berarti bahwa variabel kinerja karyawan dapat secara bersama-sama dijelaskan oleh variabel kepemimpinan, fasilitas kerja, kompetensi dan pembagian kerja.

\section{Pembahasan}

\section{Pengaruh Fasilitas Kerja Terhadap Kinerja Karyawan}

Fasilitas kerja merupakan suatu bentuk pelayanan bagi instansi terhadap karyawan agar menunjang kinerja dalam memenuhi kebutuhan karyawan, sehingga dapat meningkatkan kinerja karyawan (Robbins,2013). Hasil pengujian regresi fasilitas kerja berpengaruh positif terhadap kinerja karyawan sedangkan pada pengujian hipotesis nilai signifikansi hasil sebesar 0,014 lebih kecil dari 0,05 yang artinya fasilitas kerja juga berpengaruh signifikanterhadap kinerja karyawan serta hasil penelitian yang dilakukan mendukung hasil penelitian dari Sri Wahyuni (2014) dan Isnan Munawirsyah (2017) yang menyatakan fasilitas kerja berpengaruh positif dan signifikan terhadap kinerja karyawan.

\section{Pengaruh Kepemimpinan Terhadap Kinerja Karyawan}

Young (2011) menyatakan pengertian kepemimpinan yaitu bentuk dominasi yang didasari atas kemampuan pribadi yang sanggup mendorong atau mengajak orang lain untuk berbuat sesuatu yang berdasarkan penerimaan oleh kelompoknya, dan memiliki keahlian khusus yang tepat bagi situasi yang khusus. Hasil pengujian regresi menghasilkan kepemimpinan berpengaruh positif terhadap kinerja karyawan sedangkan pada pengujian hipotesis nilai signifikansi hasil sebesar 0,001 lebih kecil dari 0,05 yang artinya kepemimpinan juga berpengaruh signifikan terhadap kinerja karyawan. Hasil penelitian ini mendukung hasil penelitian dari Chairuddin Surya Putra (2014) dan Estu Aprilian (2017).

\section{Pengaruh Kompetensi Terhadap Kinerja Karyawan}

Ahsan (2011) mengemukakan bahwa sebagai pengetahuan, keterampilan, dan kemampuan yang dikuasai oleh seseorang yangtelah menjadi bagian dari dirinya, sehingga dapat melakukan perilaku-perilaku kognitif, afektif, dan psikomotorik dengan sebaik-baiknya. Hasil pengujian regresi menghasilkan kompetensi berpengaruh positif terhadap kinerja karyawan, sedangkan pada pengujian hipotesis nilai signifikansi hasil sebesar 0,026 lebih kecil dari 0,05 yang artinya variabel kompetensi juga berpengaruh signifikan terhadap kinerja karyawan. Hasil penelitian ini mendukung hasil penelitian Faustyna (2014) dan Fansyuri Ilham Mudayana (2016). 


\section{Pengaruh Pembagian Kerja Terhadap Kinerja Karyawan}

Pembagian tugas adalah hasil analisis pekerjaan sebagai rangkaian kegiatan atau proses menghimpun dan mengolah informasi mngenai pekerjaan. Hasil pengujian regresi menghasilkan pembagian kerja berpengaruh positif terhadap kinerja karyawan, sedangkan pada pengujian hipotesis nilai signifikansi hasil sebesar 0,003 lebih kecil dari 0,05 yang artinya variabel pembagian kerja juga berpengaruh signifikan terhadap kinerja karyawan. Hasil penelitian ini mendukung hasil penelitian dari Ferdy Roring (2017) dan Farlane S. Rumokoy (2016).

\section{Kesimpulan}

\section{PENUTUP}

1. Fasilitas kerja berpengaruh positif dansignifikan terhadap kinerja karyawan yang berarti apabila fasilitas kerja semakin ditingkatkan maka akan meningkatkan kinerja karyawan.

2. Kepemimpinan berpengaruh positif dan signifikan terhadap kinerja karyawan yang berarti apabila kepemimpinan semakin baik maka akan meningkatkan kinerja karyawan.

3.Kompetensi berpengaruh positif dan signifikan terhadap kinerja karyawan yang berarti apabila kompetensi semakin ditingkatkan maka akan meningkatkan kinerja karyawan.

4. Pembagian kerja berpengaruh positif dan signifikan terhadap kinerja karyawan yang berarti apabila pembagian kerja semakin baik maka akan meningkatkan kinerja karyawan.

\section{Saran}

1. Hasil pengujian deskriptif pada fasilitas kerja pada indikator alat komunikasi mendapatkan skor terendah, disarankan agar PT. Borobudur Oto Mobil memberikan alat komunikasi tambahan seperti tablet untuk mendukung kerja karyawan sehingga mampu memaksimalkan kinerja karyawan marketing.

2. Hasil pengujian deskriptif pada kepemimpinan pada indikator memanfaatkan sumber daya mendapatkan skor terendah, disarankan agar pimpinan PT. Borobudur Oto Mobil untuk lebih meningkatkan dalam pemanfaatan sumber daya melalui menganalisis beban kerja masing-masingkaryawan sehingga semua sumber daya bisa dimanfaatkan secara optimal.

3. Hasil pengujian deskriptif pada variabel kompetensi pada indikator kepedulian mendapatkan skor terendah, disarankan agar pimpinan PT. Borobudur Oto Mobil untuk lebih menjaga sifat peduli karyawan dengan cara memberikan evaluasi agar mendekatkan pimpinan PT. Borobudur Oto Mobil dengan karyawan marketing.

4. Hasil pengujian deskriptif pada pembagian kerja pada indikator tingkat kenyamanan karyawan mendapatkan skor terendah, disarankan agar PT. Borobudur Oto Mobil memberikan kenyamanan karyawan dalam bekerja dengan cara memberikan asuransi jiwa kepada semua karyawan.

\section{DAFTAR PUSTAKA}

Agung Prihantoro. (2015). Pengaruh Motivasi Kerja, Disiplin Kerja, Lingkungan Kerja dan Komitmen Terhadap Kinerja Kauawan. Jurnal EMBA Vol 2 No 3.

Ataunur, Ilman. (2015). Analisis pengaruh kompetensi dan pelatihan terhadap kinerja karyawan. Jurnal EMBA Vol 3 No 2.

Augusty Ferdiunand. (2013). Metode Penelitian Manajemen. Semarang: BP. UNDIP.

Avin Fadila Helmi. (1996, Desember). Disiplin Kerja. Edisi Khusus Ulang Tahun XXXII. 
Avin Fadilla Helmi. (1996, 12 Senin). Disiplin Kerja. Edisi Khusus Ulang Tahun XXXII.

Bryan Johannes Tampi. (2014). Analisis Pengaruh Gaya Kepemimpinan dan Motivasi Terhadap Kinerja Karyawan. Jurnal "Acta Diurnal" Volume III.NO.4.Tahun 2014.

Dwi Agung Nugroho Arianto. (2015). Pengaruh Kedisiplinan, Lingkungan Kerja dan Budaya Kerja Terhadap Kinerja Karyawan. Jurnal Perilaku Organisasi Vol 1 No 4.

Ernawaty Nasution. (2014). Analisis Pengaruh Motivasi kerja dan Kepemimpinan Terhadap Kinerja Karyawan. Jurnal Al Bayan/VOL.20,NO29,Januari-Juni 2014.

Evy Amalia. (2015). Pengaruh Motivasi Kerja dan Disiplin Kerja Terhadap Kinerja Karyawan. Jurnal MSDM Vol 1 No IFaustyna . (2014). Analisis pengaruh kompetensi dan komitmen pada tugas terhadap kinerja karyawan. Jurnal Ilmu Manajemen Dan Bisnis Vol 3 No 4.

Gomes, F. C. (2003). Manajemen Sumber Daya Manusia. Yogyakarta: ANDI YOGYAKARTA.

Harun Islami. (2013). Pengaruh Lingkungan Kerja, Karakteristik Individu dan Motivasi Kerja Terhadap Kinerja Karyawan. Jurnal Manajemen Vol 3 No

2.

I Putu Sedhana Yasa. (2015). Pengaruh Kompensasi dan Lingkungan Kerja Terhadapn Kepuasan Kerja dan Kinerja Karyawan. Jurnal EMBA Vol 1 No 5.

Imam Ghozali. (2011). Aplikasi analisis mulitivariate dengan progam ibm SPSS21. Semarang: BP. UNDIP.

Impiansi, Romantika Citra. (2016). Analisis pengaruh kecerdasan emosional, komunikasi dan lingkungan kerja terhadap kinerja karyawan. Jurnal Manajemen Sumber Daya Manusia Vol 3 No 5.

Irawaty A. Khahar. (2008). Disiplin Kerja, Kepemimpinan dan Lingkungan Kerja Terhadap Kinerja Karyawan. Jurnal Studi Perpustakaan dan Informasi, Vol4 NO1 Juni2008.

Jessica Martha Kusuma. (2014). Pengaruh Insentif, Motivasi Kerja dan Disiplin Kerja Terhadap Kinerja KARYAWAN. Jurnal EMBA Vol 1 No 4. 
Kusmaningtyas, Amiartuti. (2015). Pengaruh Budaya Organisasi, Kepuasan Kerja Dan Lingkungan Kerja Terhadap Kinerja Karyawan. Jurnal EMBA Vol 2 No 5.

Kusmanto. (2017). Analisis pengaruh pengawasan, motivasi dan pembagian kerja terhadap kinerja karyawan. Jurnal Riset Manajemen Vol 3 No 2.

Lidya T. Rumengan. (2015). Analisis Kompensasi dan Kepemimpinan Terhadap Kinerja Karyawan. Jurnal EMBA VOL3 NO1 Maret 2015.

Mangkunegara, Anwar Prabu. (2013). Manajemen Sumber Daya Manusia. Jakarta: Erlangga.

Marpaung, M. (2014). Analisis Disiplin Kerja dan Kompensasi Terhadap Kinerja Karyawan. Jurnal Ilmiah Widya.Volume2.NO.1 Maret-April 2014. Maulidiah, Virginia. (2015). Analisis pengaruh pelatihan, pengalaman kerja dan promosi jabatan terhadap kinerja karyawan. Jurnal EMBA Vol 3 No 7.

Nana Suryana. (2015). Pengaruh Kepemimpinan dan Motivasi Kerja Terhadap Kinerja Karyawan. Jurnal Organisasi Vol 3 No 5.

Nel Arianty. (2014). Motivasi Kerja Terhadap Kinerja Karyawan. Jurnal Manajemen Bisnis VOL 14 NO 02 OKTOBER 2014Nugroho, Setyo. (2017). Pengaruh Pelatihan Kerja, Motivasi Dan Pemberian Insentif Terhadap Kinerja. Jurnal EMBA Vol 2 No 4.

Pujiati. (2015). Pengaruh Budaya Organisasi dan Lingkungan Kerja dan Motivasi Kerja Terhadap Kinerja Karyawan. Jurnal MSDM Vol 3 No 7.

Putra, Chairuddin Surya. (2014). Analisis pengaruh kepemimpinan, budaya organisasi dan motivasi kerja terhadap kinerja karyawan. Jurnal Manajemen Vol 3 No 5.

Putra, Chairuddin Surya. (2014). Analisis pengaruh kepemimpinan, motivasi kerja dan budaya organisasi terhadap kinerja karyawan. Jurnal EMBA Vol 3 No 4.

Robbins, Stephen P. (2014). Manajemen Sumber Daya Manusia Jili II. Bandung: Alfabeta.

Roring, Ferdy. (2017). Analisis pengaruh kepemimpinan, pembagian kerja dan kompensasi terhadap kinerja 
karyawan. Jurnal Manajemen Dan Bisnis Vol 4 No8.

Sangki, Richard Y. (2014). Lingkungan Kerja, Budaya Kerja Dan Semangat Kerja Terhadap Kinerja Karyawan . Jurnal EMBA 539 Vol.2 No.3 .

Septiani, Virginia Maulidiah. (2015). Analisis pengaruh pelatihan, pengalaman kerja dan promosi jabatan terhadap kinerja karyawan. Jurnal Manajemen Vol 2 No6.

Sudirjo, Frans. (2015). Pengaruh Komitmen Organisasi, Motivasi, Kapabilitas Dan Kepuasan Kerja Terhadap Kinerja. Serat Acitya - Jurnal Ilmiah UNTAG Semarang Vol. 4 No. 3, .

Sumaki, Windy J. (2015). Analisis pengaruh disiplin kerja, budaya organisasi dan komunikasi terhadap kinerja karyawan. Jurnal EMBA Vol 7 No 4.

Susilo Toto Raharjo. (2013). Analisis Pengaruh Kepemimpinan, Budaya Organisasi, dan Kompensasi terhadap Kinerja Karyawan. Jurnal Studi Manajemen dan Organisasi.Volume3, Nomor 2 Juli Tahun 2013.

Temon Kusmono. (2014). Pengaruh Budaya Organisasi, Motivasi Kerja dan Kepuasan Kerja Terhadap Kinerja Karyawan. Jurnal MSDM Vol 2 No 6.

Wahyuni, Sri. (2014). Analisis pengaruh motivasi kerja, pelatihan dan fasilitas kerja terhadap kinerja karyawan. Jurnal Manajemen Dan Bisnis Vol 3 No 4.

Wijayanti, Desi Putri. (2017). Analisis manajemen pengetahuan, pengetahuan personal dan prosedur kerja terhadap kinerja karyawan. Jurnal Ilmu Manajemen Vol 3 No 5.

Yoga Arsyendra. (2015). Pengaruh Motivasi Kerja dan Disiplin Kerja Terhadap Kinerja Karyawan. Jurnal MSDM Vol 5 No 1. 